Daniel De Backer

\section{Reply to Scheeren: monitoring the microcirculation in the critically ill patient: reflectance spectroscopy}

Accepted: 15 January 2011

Published online: 11 March 2011

(C) Copyright jointly held by Springer and ESICM 2011

This reply refers to the comment available at: doi:10.1007/s00134-011-2197-1.

\section{Dear Editor,}

We read with interest the comments by Scheeren [1] on our review article on the methods for evaluating the microcirculation [2]. The section on reflectance spectroscopy was indeed relatively short not because of lack of experience but on purpose, due to some methodological concerns with recent developments of the technique. Indeed, as mentioned in our review, $\mathrm{O}_{2} \mathrm{C}$ (Lea, Giessen, Germany), the only commercially available version of reflectance spectroscopy, provides the mean value of $\mathrm{SO}_{2}$ only, which is unfortunate, as information on heterogeneity is lost.

More importantly, the relevance of reported mean $\mathrm{SO}_{2}$ value can be questioned. It is false to state, as Scheeren did in his letter, that this value reflects the oxygen saturation of haemoglobin $\left(\mu \mathrm{HbO}_{2}\right)$ at the venous end of the capillaries (the so-called last meadow). Reflectance spectroscopy devices measure the microvascular $\mathrm{O}_{2}$ saturation of all vessels within the beam, which probes an area of $0.09 \mathrm{~mm}^{2}$ (a circle of $200-\mu \mathrm{m}$ diameter) over a depth of $250 \mu \mathrm{m}$ [3]. This sampling volume is far better than many other techniques of $\mathrm{O}_{2}$ measurement, and is likely to decrease with refinements of the technique, but still comprises many vessels of different nature. The mean value seems to be mostly affected by arterial (or arteriolar) vessels. In Sakr et al's study [4], sublingual $\mathrm{SO}_{2}$ was $91 \pm 5 \%$ in healthy volunteers (interquartile range 87-96). This value is incompatible with measurements at the venous end of capillaries as it would imply that $\mathrm{VO}_{2}$ is close to 0 . Hence, great caution should be taken when looking at average measurements of $\mathrm{SO}_{2}$ to assess the microcirculation, whatever the device used.

\section{References}

1. Scheeren T (2011) Monitoring the microcirculation in the critically ill patient: reflectance spectroscopy. Intensive Care Med. doi: 10.1007/s00134-011-2197-1

2. De Backer D, Ospina-Tascon G, Salgado D, Favory R, Creteur J, Vincent JL (2010) Monitoring the microcirculation in the critically ill patient: current methods and future approaches. Intensive Care Med 36:1813-1825

3. Temmesfeld-Wollbrück B, Szalay A, Mayer K, Olschewski H, Seeger W, Grimminger F (1998) Abnormalities of gastric mucosal oxygenation in septic shock. Am J Respir Crit Care Med 157:1586-1592

4. Sakr Y, Gath V, Oishi J, Klinzing S, Simon TP, Reinhart K, Marx G (2010) Characterization of buccal microvascular response in patients with septic shock. Eur J Anaesthesiol 27:388-394

D. De Backer ( $)$

Department of Intensive Care,

Erasme University Hospital,

808 Route de Lennick, 1070 Brussels,

Belgium

e-mail: ddebacke@ulb.ac.be

Tel.: +32-2-5553380

Fax: +32-2-5554698 